\title{
Oxygen Saturation as a Predictor of Outcome in COVID-19
}

Authors

\author{
P. Paranthaman ${ }^{1}$, K.Dhananjayan ${ }^{2 *}$, Raheema M.A.M ${ }^{3}$ \\ ${ }^{1}$ HOD, Department of General Medicine, Kilpauk Medical College \\ ${ }^{2}$ Associate Professor, Department of General Medicine, Thiruvarur Medical College \\ ${ }^{3}$ Post Graduate Student, Department of General Medicine, Kilpauk Medical College \\ *Corresponding Author \\ K.Dhananjayan
}

\begin{abstract}
This study aims to identify the association between oxygen saturation on admission and outcome in COVID 19. This study enrolled 802 adult patients admitted in a tertiary care hospital with confirmed COVID 19 between November 2020 to January 2021. Of the 802 patients, 653 (81.42\%) patients were discharged and $149(18.58 \%)$ patients died. The patients were categorized into four categories-those with oxygen saturation on admission 90-100\%, 80-89\%, 70-79\% and less than $70 \%$ and the respective mortality rates were $6.25 \%, 8.5 \%, 39.66 \%$ and $83.33 \%$. Oxygen saturation at admission and the outcome was compared with age and gender. Statistical analysis was done by Chi-Square test and p value was calculated. This study concludes that saturation less than $80 \%$ on admission and age more than 55 years is a predictor of in hospital mortality and is independently associated with the outcome.
\end{abstract}

Keywords: Oxygen Saturation on admission, outcome, Chi square test.

\section{Introduction}

In December 2019, Wuhan, China, became the center of an outbreak of atypical pneumonia caused by the severe acute respiratory syndrome coronavirus 2 (SARS-CoV-2) ${ }^{[1]}$. The cases of coronavirus disease spread rapidly throughout China and other countries and the outbreak was declared a pandemic by the World Health Organization (WHO) on March 11, 2020.

The majority of COVID 19 patients experience mild to moderate respiratory illness ${ }^{[2] .}$ However, $20 \%$ of patients are severe and critically ill cases who are at risk of progressing to acute respiratory distress syndrome (ARDS), acute respiratory failure or multiple organ dysfunction ${ }^{[3]}$. This study aims to identify the association between oxygen saturation on admission and the outcome in COVID 19.

\section{Methods}

Study Design and Participants

\section{Inclusion Criteria}

This study included patients who received in patient treatment for confirmed COVID 19 disease at a tertiary care hospital in between November 2020 and January 2021. Confirmed COVID 19 cases were those with a positive result on real time reverse transcriptase polymerase chain reaction with oropharyngeal and nasal swabs.

\section{Exclusion Criteria}

Those with the below conditions were excluded.

(I) Known respiratory Illness eg., Chronic obstructive pulmonary disease/Interstitial lung disease /Bronchial asthma/Lung carcinoma/Pulmonary Tuberculosis

(II) Congestive cardiac failure 
(III) Chronic kidney disease with volume overload status

(IV) Any noxious substance intake

The oxygen saturation at admission was measured by pulse oximeter. Using these inclusion and exclusion criteria, 802 patients were enrolled in the study.

\section{Statistical Analysis}

Statistical analysis was performed using SAS, version 9.4 (SAS Institute Inc.). Counting data is presented as percentages. All values were rounded off to two decimals. The comparison of categorical values was evaluated using the Chi-Square test. A two-sided p-value of $<0.05$ was accepted for statistical significance.

\section{Results}

Of the 802 patients treated for COVID 19, 149 (18. $58 \%$ ) died due to complications of COVID 19 and 653 (81. 42\%) were discharged. In the study population, $483(60.22 \%)$ were male and 319 $(39.78 \%)$ were female. The mortality rates in males was $19.83 \%$ and females was $16.61 \%$. The lowest age in the study was 25 years and the highest age was 87 years.

The number of cases with oxygen saturation on admission with $90-100 \%$ was 240 (29.93\%), 80-89\% was $363(45.26 \%), 70-79 \%$ was $121(15.09 \%)$ and less than $70 \%$ was $78(9.72 \%)$. The survival rates for those with saturation between $90-100 \%$ was $93.75 \%, 80-89 \%$ was $91.4 \%, 70-79 \%$ was $60.33 \%$ and less than $70 \%$ was $16.66 \%$. The mortality rates for those with oxygen saturation of $90-100 \%$ was $6.25 \%, 80-89 \%$ was $8.5 \%, 70-79 \%$ was $39.66 \%$ and less than $70 \%$ was $83.33 \%$.

Chi square test was calculated for these rates and $\mathrm{p}$ value was found to be $<0.00001$ and was statistically significant. On comparing oxygen saturation at admission and outcomes with the age and gender, more mortality was observed in age above 55 years while it was similar in both genders.
Table 1: Oxygen Saturation and Outcome

\begin{tabular}{|l|c|c|c|}
\hline $\begin{array}{l}\text { OXYGEN } \\
\text { SATURATION } \\
\text { AT } \\
\text { ADMISSION }\end{array}$ & $\begin{array}{c}\text { Number } \\
\text { of cases }\end{array}$ & Discharged & Died \\
\hline $90-100 \%$ & $\begin{array}{c}240 \\
(29.93 \%)\end{array}$ & $225(93.75 \%)$ & $\begin{array}{c}15 \\
(6.25 \%)\end{array}$ \\
\hline $80-89 \%$ & 363 & $342(91.4 \%)$ & $\begin{array}{c}21 \\
(8.5 \%)\end{array}$ \\
\hline $70-79 \%$ & $(45.26 \%)$ & $73(60.33 \%)$ & $\begin{array}{c}48 \\
(39.66 \%)\end{array}$ \\
\hline$<70 \%$ & $(15.09 \%)$ & & $\begin{array}{c}65 \\
(83.33 \%)\end{array}$ \\
\hline
\end{tabular}

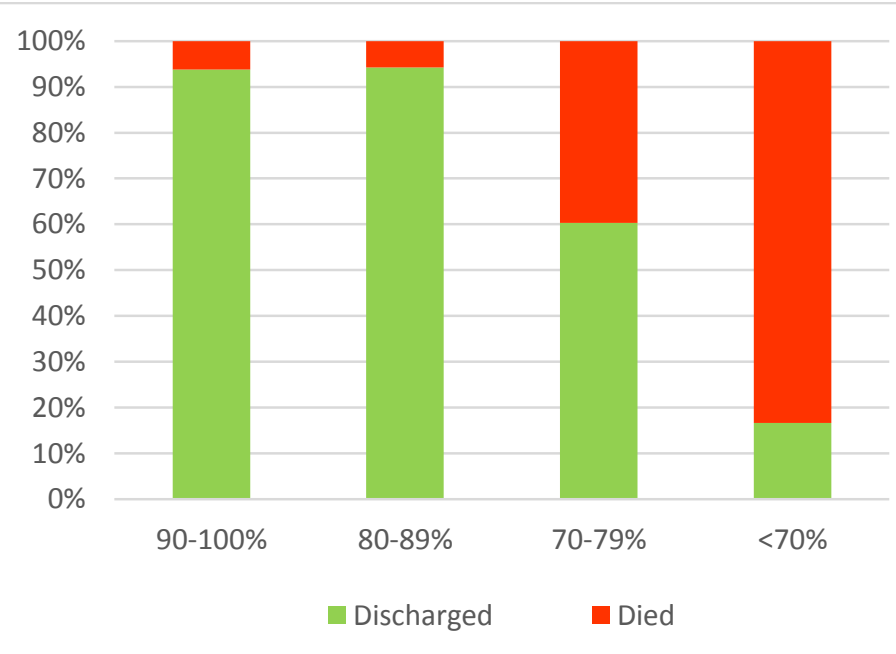

Figure 1: Graphical representation of Oxygen Saturation and Outcome

\section{Discussion}

This study is the first report of association of oxygen saturation and outcome involving a large population of hospitalized COVID 19 patients in India. In our study it has been established that saturation of less than $80 \%$ on admission was associated with increase in hospital mortality.

The study is consistent with other research studies conducted all over the world. Study in China done by Jiang Xie et al., concludes that hypoxemia was independently associated with in-hospital mortality in COVID-19 and saturation levels greater than $90 \%$ showed a higher likelihood of survival ${ }^{[4]}$. Fernando et. Al. has concluded that oxygen saturation below $90 \%$ on admission is a strong predictor of in hospital mortality in patients with COVID 19 in Peru $^{[5]}$. 
Table 2: Oxygen Saturation and Outcome based on age

\begin{tabular}{|c|c|c|c|c|c|c|c|c|}
\hline \multirow{2}{*}{$\begin{array}{l}\text { OXYGEN } \\
\text { SATURATION AT } \\
\text { ADMISSION } \\
\end{array}$} & \multicolumn{2}{|c|}{ 25-35 YEARS } & \multicolumn{2}{|c|}{ 36-45 YEARS } & \multicolumn{2}{|c|}{ 46-55 YEARS } & \multicolumn{2}{|c|}{$>55$ YEARS } \\
\hline & DISCHARGED & DIED & DISCHARGED & DIED & DISCHARGED & DIED & DISCHARGED & DIED \\
\hline $90-100 \%$ & $30(100 \%)$ & $0(0 \%)$ & $27(87.10 \%)$ & $4(12.90 \%)$ & $97(98.98 \%)$ & $1(1.02 \%)$ & $71(87.65 \%)$ & $10(12.35 \%)$ \\
\hline $80-89 \%$ & $54(96.43 \%)$ & $1(3.58 \%)$ & $80(91.96 \%)$ & $7(8.05 \%)$ & $163(99.39 \%)$ & $1(0.61 \%)$ & $45(78.95 \%)$ & $12(21.05 \%)$ \\
\hline $70-79 \%$ & $20(95.24 \%)$ & $1(4.76 \%)$ & $18(78.26 \%)$ & $5(21.74 \%)$ & $15(62.5 \%)$ & $9(37.5 \%)$ & $20(37.74 \%)$ & $33(62.26 \%)$ \\
\hline$<70 \%$ & $4(28.57 \%)$ & $10(71.43 \%)$ & $2(6.45 \%)$ & $29(93.55 \%)$ & $3(20 \%)$ & $12(80 \%)$ & $4(22.22 \%)$ & $14(77.78 \%)$ \\
\hline TOTAL & $108(90 \%)$ & $12(10 \%)$ & $127(73.84 \%)$ & $45(26.16 \%)$ & $278(92.36 \%)$ & $23(7.64 \%)$ & $140(66.99 \%)$ & $69(33.01 \%)$ \\
\hline
\end{tabular}

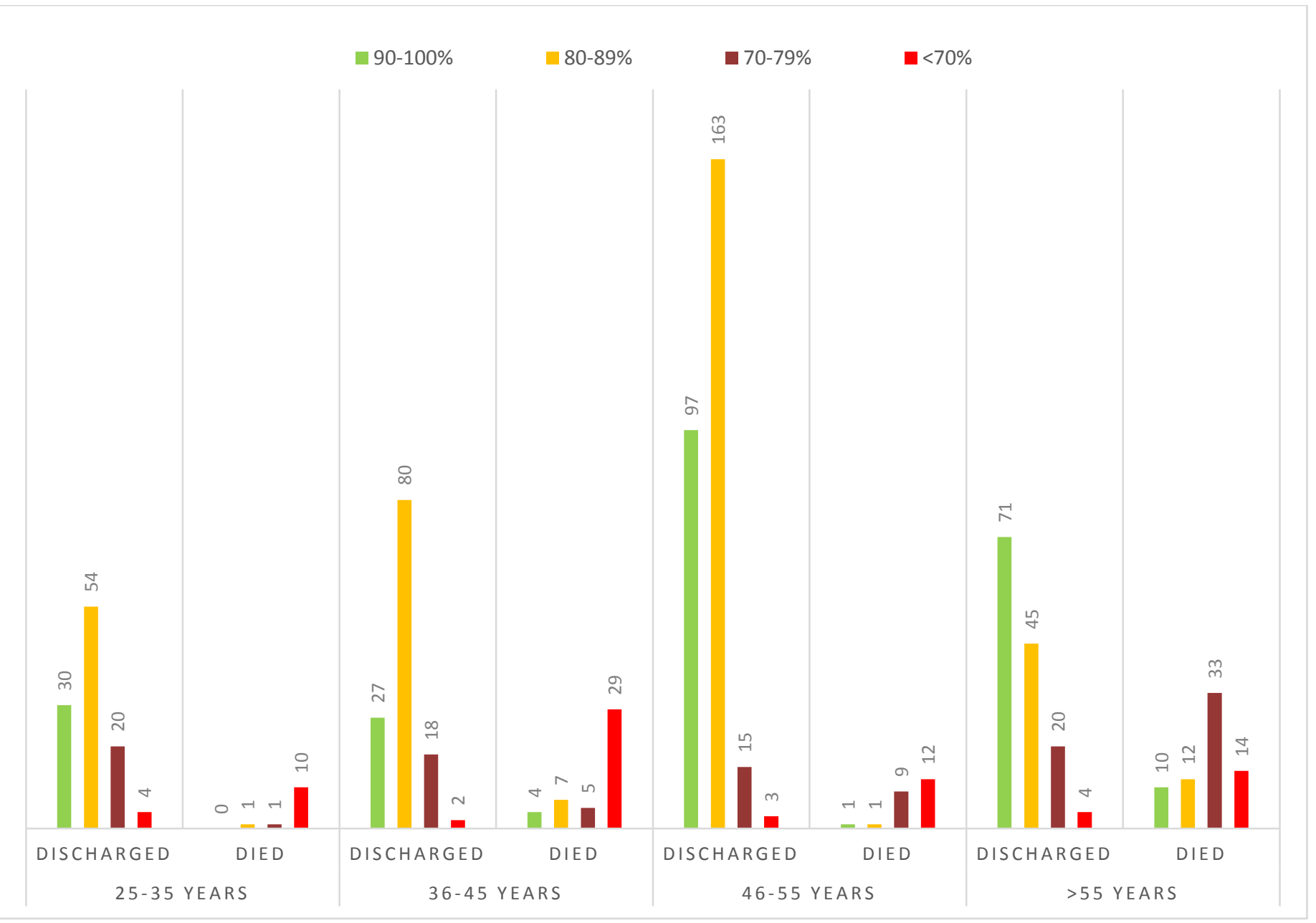

Figure 2: Graphical representation of Oxygen Saturation and Outcome based on age

Table 3: Oxygen Saturation and Outcome based on gender

\begin{tabular}{|c|c|c|c|c|}
\hline \multirow{2}{*}{$\begin{array}{l}\text { OXYGEN } \\
\text { SATURATION } \\
\text { AT ADMISSION }\end{array}$} & \multicolumn{2}{|c|}{ MALES } & \multicolumn{2}{|c|}{ FEMALES } \\
\hline & DISCHARGED & DIED & DISCHARGED & DIED \\
\hline $90-100 \%$ & $140(93.33 \%)$ & $10(6.67 \%)$ & $85(94.45 \%)$ & $5(5.55 \%)$ \\
\hline $80-89 \%$ & $217(93.13 \%)$ & $16(6.87 \%)$ & $125(96.15 \%)$ & $5(3.85 \%)$ \\
\hline $70-79 \%$ & $42(57.53 \%)$ & $31(42.47 \%)$ & $31(64.58 \%)$ & $17(35.42 \%)$ \\
\hline$<70 \%$ & $6(22.22 \%)$ & $21(77.77 \%)$ & $7(13.73 \%)$ & $44(86.27 \%)$ \\
\hline
\end{tabular}




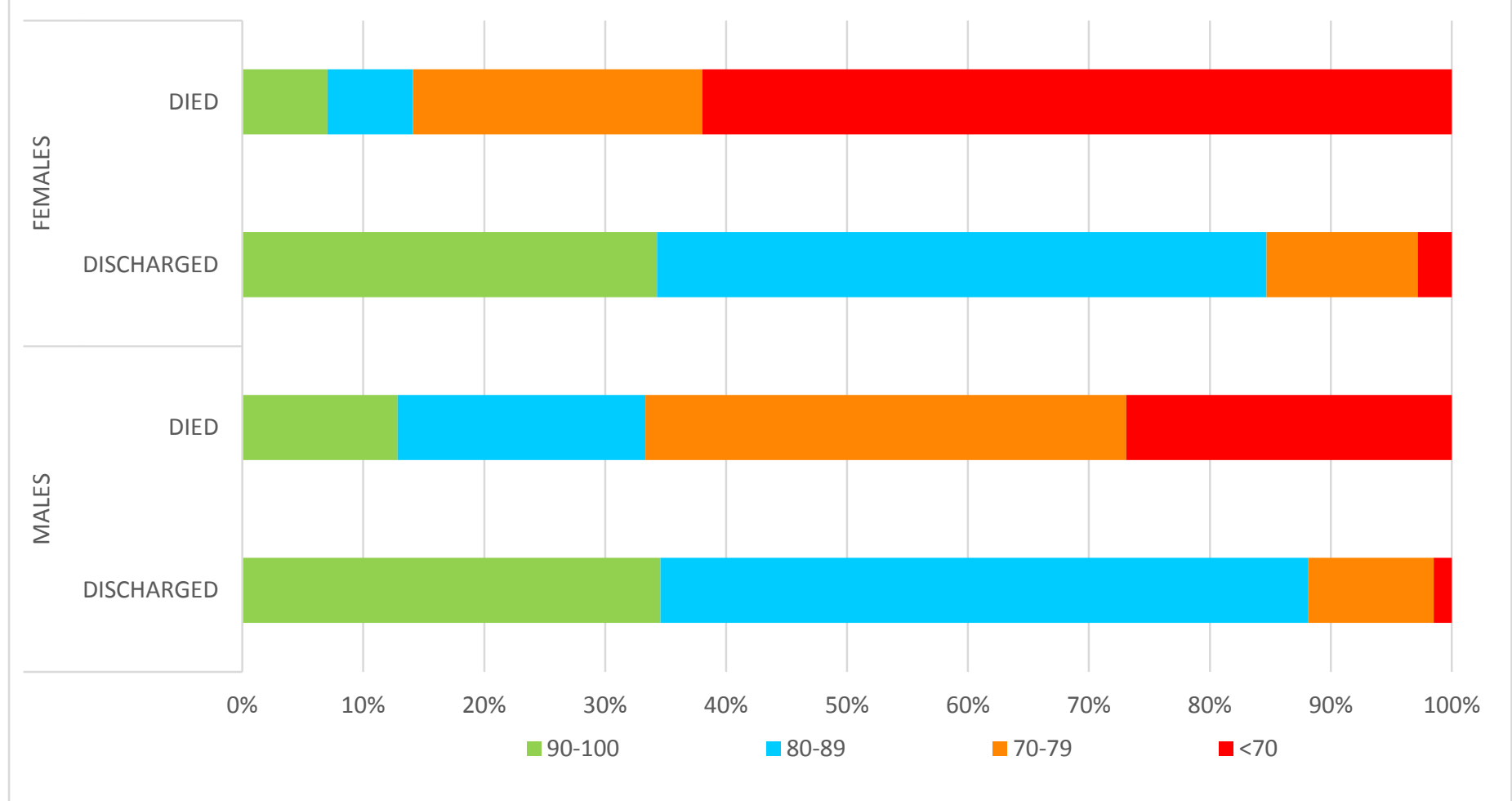

Figure 3: Graphical representation of Oxygen Saturation and Outcome based on gender

Hypoxia and inflammation are intertwined at the molecular, cellular, and clinical level. Clinical events that produce acute hypoxemia enhance various cytotoxic functions of neutrophils and can promote hyperinflammation ${ }^{[6]}$. Adult respiratory distress syndrome is one of the main complications of COVID-19. Higher the hypoxemia, higher the mortality in ARDS and patients become refractory to standard critical care interventions ${ }^{[7]}$. More mortality was observed when the age was more than 55 years and this could be related to the function of defence cells $\mathrm{T}$ and $\mathrm{B}$, and to the excess production of type 2 cytokines, which can lead to prolonged pro-inflammatory response, potentially leading to poor outcome ${ }^{[8]}$.Thus, early identification and timely treatment of critical cases are crucial for decreasing the number of deaths and increasing survival.

The main limitation of the study is that the day of swab positivity and day of illness on admission was different for each one and could not be matched. Those who were admitted would belong to moderate and severe disease so the exact mortality rates would be lower. Moreover, the results were obtained from a single center.

\section{Conclusion}

In conclusion, lower the oxygen saturation ( $\mathrm{Spo} 2$ less than $80 \%$ ) on admission and age more than 55 years was associated with higher in-patient mortality. Early identification of hypoxemia must be done and timely access to care has to be given which can help prevent the complications of persistent hypoxemia. A marginal fall in oxygen saturation from resting level should be taken as an alarming sign especially when associated with symptoms of fever more than 5 days, dry cough and breathlessness on exertion even when oxygen saturation is more than $94 \%$ on admission. Hence by we can prevent rapid desaturation and its related complications. Thus, oxygen saturation can be a reliable predictor for in-hospital mortality and can be effectively used to triage the patients as well as to modify their treatment protocols.

\section{References}

1. Phelan AL, Katz R, Gostin LO. The Novel Coronavirus Originating in Wuhan, China: Challenges for Global Health Governance. JAMA.

2020. 
https://doi.org/10.1001/jama.2020.1097 PMID: 31999307.

2. WHO.2020.https://www.who.int/healthtopics/coronavirus\#tab=tab_3.

3. Wu Z, McGoogan JM. Characteristics and important lessons from the corona virus disease 2019 (COVID 19) outbreak in China : summary of a report of 72314 cases from the Chinese center for disease control and prevention. JAMA 2020;323(13):1239 42. https://doi.org/10.1001/jama.2020.2648.

4. Xie J, Covassin N, Fan Z, Singh P, Gao W, $\mathrm{LiG}$, et.al. Association Between Hypoxemia and Mortality in Patients With COVID19.Mayo Clin Proc.2020;95:11381147.http://doi.org/10.1016/j.mayocp.

5. Fernando Mejía, Carlos Medina, Enrique Cornejo , Enrique Morello, Sergio Vásquez, Jorge Alave, Alvaro Schwalb, Germán Málaga - Oxygen saturation as a predictor of mortality in hospitalized adult patients with COVID-19 in a public hospital in Lima, Peru. PMID: 33370364 PMCID: PMC7769479 DOI: 10.1371/journal.pone.0244171

6. Eltschizg HK, Carmeliet P. Hypoxia and inflammation, $\mathrm{N}$ Engl J Med 2011; 364: 656-665.

https://doi.org/10.1056/NEJMra0910283 PMID:21323543

7. Pipeling MR, Fan E. Therapies for refractory hypoxemia in acute respiratory distress syndrome.JAMA.2010;304:2521-

2527.https://doi.org/10.1001/jama.2010.175 2 PMID:21139113

8. Opal SM, Girard TD and Ely EW (2005) The immunopathogenesis of sepsis in elderly patients. Clinical Infectious Diseases 41(suppl.7),S504-S512

9. Zhou F, Yu T, Du R, Fan G, Liu Y, Liu Z, et al. Clinical course and risk factors for mortality of adult in patients with COVID19 in Wuhan, China: a retrospective cohort study. Lancet. 2020;395: 1054-1062. 10.1016/S0140-6736(20)30566-3
10. Sousa GJB, Garces TS, Cestari VRF, Florêncio RS, Moreira TMM, Pereira MLD. Mortality and survival of COVID-19. Epidemiol Infect. 2020;148: e123 10.1017/S0950268820001405

11. Wang K, Zuo P, Liu Y, Zhang M, Zhao X, Xie $S$, et al. Clinical and laboratory predictors of in-hospital mortality in patients with COVID-19: a cohort study in Wuhan, China. Clin Infect Dis. 2020. 10.1093/cid/ciaa538

12. Hazal Cansu Acar, Günay Can, Ridvan Karaali, Şermin Börekçi, İlker İnanç Balkan, Bilun Gemicioğlu, Dildar Konukoğlu, Ethem Erginöz, Mehmet Sarper Erdoğan \& Fehmi Tabak - An easy-to-use nomogram for predicting in-hospital mortality risk in COVID-19: a retrospective cohort study in a university hospital BMC Infectious Diseases volume 21, Article number: 148 (2021).

13. Richardson S, Hirsch JS, Narasimhan M, Crawford JM, McGinn T, Davidson KW, et al. Presenting Characteristics, Comorbidities, and Outcomes Among 5700 Patients Hospitalized With COVID-19 in the New York City Area. JAMA. 2020. Doi: 10.1001/jama.2020.6775. PMID:32320003

14. Yang X, Yu Y, Xu J, Shu H, Xia J 'an, Liu $\mathrm{H}$, et al. Clinical course and outcomes of critically ill patients with SARS-CoV-2 pneumonia in Wuhan, China: a singlecentered, retrospective, observational study. Lancet Respir Med. 2020;8: 475-481. doi: 10.1016/S2213-2600(20)30079-5. PMID :32105632

15. Pan F, Yang L, Li Y, Liang B, Li L, Ye T, et al. Factors associated with death outcome in patients with severe coronavirus disease-19 (COVID-19): a case-control study. Int J Med Sci. 2020;17: 1281-1292. doi: 10.7150/ijms.46614. PMID:32547323. 